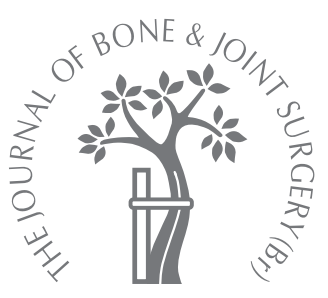

R. P. Baker, T. C. B. Pollard, S. J. EastaughWaring, G. C. Bannister

From the Avon Orthopaedic Centre, Bristol, United Kingdom

\title{
A medium-term comparison of hybrid hip replacement and Birmingham hip resurfacing in active young patients
}

We compared the medium-term clinical and radiological results of hybrid total hip replacement (THR) with metal-on-metal Birmingham hip resurfacing (BHR) in two groups of 54 young patients matched for age, gender, body mass index and pre-operative levels of activity.

The clinical outcome was assessed by the University of California, Los Angeles (UCLA) activity score, the Oxford Hip Score (OHS) and the EuroQol scores. Radiologically, all hips were assessed for migration and osteolysis, the hybrid THRs for polyethylene wear and the BHRs for a pedestal sign. The mean follow-up of the patients with a hybrid THR was ten years and for those with a BHR, nine years. Four patients with a hybrid THR and one with a BHR had died. In each group five were lost to follow-up. The revision rate of the hybrid THRs was $16.7 \%$ (9 of 54) and of the BHRs $9.3 \%$ (5 of 54$)(p=0.195)$. Radiographs of a further eight hybrid THRs demonstrated wear and osteolysis, and they await revision $(p=0.008)$. Of the unrevised BHRs $\mathbf{9 0} \%$ had radiological changes, of which approximately $\mathbf{5 0} \%$ had progressed over the previous four years. All hybrid THRs demonstrated linear polyethylene wear with a mean of $1.24 \mathbf{~ m m}$ (0.06 to 3.03). The BHRs recorded superior OHS ( $p=0.013)$, UCLA $(p=0.008)$, and EuroQol visual analogue scores $(p=0.009)$.

After nine years, patients with BHRs remained more active and had a lower rate of revision than those with hybrid THRs. Both groups demonstrated progressive radiological changes at medium-term follow-up.

Metal-on-metal hip resurfacing has been practised outside the originating centres for over a decade. These institutions report a 93\% survivorship of the Conserve Plus (Wright Medical Technology Inc., Arlington, Tennessee) after eight years, ${ }^{1}$ 93\% with the McMinn (Corin Medical Ltd, Cirencester, United Kingdom) double heat-treated design after ten years ${ }^{2}$ and 96\% with the Birmingham Hip Resurfacing (BHR; Smith \& Nephew, Memphis, Tennessee) at 12 years. $^{3}$

Metal-on-metal hip resurfacing is subject to the specific complications of fracture of the femoral neck, ${ }^{4,5}$ avascular necrosis ${ }^{6,7}$ and pseudotumour formation, ${ }^{8}$ as well as aseptic loosening and osteolysis. ${ }^{2}$ However, it has potential advantages over total hip replacement (THR) in that it preserves femoral bone stock, its hard bearing surface wears less than high density polyethylene, and its large head is associated with lower rates of dislocation.

Randomised controlled trials have shown no difference in the quality of life between metalon-metal hip resurfacing and uncemented metal-on-metal THR after 1.1 years $^{9}$ or in gait after three months, ${ }^{10}$ but the activity scores at one year are higher after metal-on-metal hip resurfacing. ${ }^{11,12}$ Matched-case controlled comparisons of metal-on-metal hip resurfacing and uncemented metal- or ceramic-on-polyethylene THR show superior function after resurfacing. ${ }^{13,14}$ While all of the aforementioned studies describe resurfacing using hybrid methods of fixation with a cemented femoral component, and an uncemented acetabular component, only one, published at two periods of follow-up, ${ }^{15,16}$ has compared resurfacing with THR with similar hybrid fixation.

This study compares 54 of the first 63 BHRs performed by the senior author (GCB) with 54 hybrid THRs matched for age, gender, body mass index (BMI) and pre-operative level of activity, which were carried out just before the BHR was introduced. We have previously reported the early ${ }^{15}$ and five-year ${ }^{16}$ results of these cohorts in which the BHRs were functionally superior to the hybrid THRs. The aim of the current study was to compare the outcome of BHR with hybrid THR at a follow-up of approximately ten years. 


\section{Patients and Methods}

Between January 1996 and April 2001, 54 hips in 53 patients (13 women, 13 hips and 40 men, 41 hips) had a hybrid THR using the cemented CPT femoral component (Zimmer, Warsaw, Indiana), with an uncemented acetabular component and a press-fit polyethylene liner. The uncemented acetabular components included 29 HarrisGalante II (Zimmer), 16 ABG II (Stryker Orthopedics, Mahwah, New Jersey), seven Zweymuller (PLUS Orthopedics, Rotkreuz, Switzerland), one PFC (DePuy International, Leeds, United Kingdom) and one Hedrocel (Implex Corp, Allendale, New Jersey). A $28 \mathrm{~mm}$ modular metal femoral head was used in 45 hips and a ceramic in nine.

Between August 1999 and April 2001, 63 hips were resurfaced using the BHR (previously Midland Medical Technologies, Birmingham, United Kingdom, now Smith \& Nephew, Memphis, Tennessee). This comprised a cemented femoral component and an uncemented hemispherical flanged hydroxyapatite- and porous-coated acetabular component. On no occasion during this period did the senior author decide at operation that a case was unsuitable for resurfacing and perform a THR instead. Of the 63 hips, two were revised for fracture of the femoral neck within six weeks of implantation and one for avascular necrosis after one year. There were six patients (six hips) who were not contactable, leaving 54 surviving BHRs in 51 patients (11 women, 13 hips and 40 men, 41 hips).

The operations were predominantly for primary osteoarthritis. ${ }^{15,16}$ All were performed through the posterior approach, which was extensile in the BHRs. No hybrid THRs had required further surgery following their primary procedure before recruitment to the study. All patients were allowed to bear full weight immediately post-operatively. Patients with BHRs commenced highimpact activity after three months but those with hybrid THRs were advised to avoid heavy manual work and high impact sport.

The BHRs were matched with hybrid THRs for gender, age at surgery (within five years), BMI (within $5 \mathrm{~kg} / \mathrm{m}^{2}$ ) and their pre-operative level of activity before it was limited by symptoms. Activity was graded using the University of California, Los Angeles (UCLA) activity score. ${ }^{17}$ We matched patients within two points on the scale. The mean age of the patients with a BHR at initial arthroplasty was 49.8 years (18 to 67 ), their mean BMI was $25.7 \mathrm{~kg} / \mathrm{m}^{2}$ (19.7 to 35.1 ) and their mean pre-operative UCLA activity score was 9.0 points (6 to 10$)$. The mean age of the patients with a hybrid THR was 50.4 years (21 to 66), their mean BMI $27.0 \mathrm{~kg} / \mathrm{m}^{2}$ (18.5 to 37.0 ) and their mean pre-operative UCLA activity score was 8.9 points (6 to 10 ).

All patients were invited to attend outpatient clinics, where they completed a questionnaire recording complications of their hip arthroplasty, the UCLA activity score, ${ }^{17}$ the Oxford hip score (OHS), ${ }^{18}$ and the EuroQol ${ }^{19}$ quality of life score. The UCLA activity score was used, as previously, with modifications for the British population. ${ }^{6,16}$ The OHS was ranked from 12 (asymptomatic) to 60 (severe) to allow comparison with previous scores. ${ }^{16}$ The EuroQol EQ-5D scores were derived from the questionnaire validated for the United Kingdom (UK TTO value set). ${ }^{16,19}$

Patients were asked to classify their running, sporting activity and heavy manual work within the last four weeks into the following categories: no trouble at all, very little trouble, moderate trouble, extreme trouble, tried but impossible and not attempted.

They were asked to record their satisfaction with the surgery as delighted, pleased, satisfied, a little disappointed and very disappointed. These measures of activity and satisfaction are not validated.

The medical notes were checked to ensure that no complications or re-operations had been missed. The early complications have been reported previously. ${ }^{15,16}$ Anteroposterior (AP) and lateral radiographs of each hip were taken and compared with the previous ones. Changes around the femoral and acetabular components of the hybrid THRs were described on the AP radiographs using the zones of DeLee and Charnley ${ }^{20}$ and Gruen, McNeice and Amstutz ${ }^{21}$ and on the lateral radiographs using the additional zones of Johnston et al. ${ }^{22}$ Linear polyethylene wear was measured by the method of Dorr and Wan. ${ }^{23}$ Radiological changes around the femoral component of the BHRs were recorded as in our previous study (Table I). ${ }^{16}$ Changes around the acetabular component in the BHRs were recorded as for the hybrid THRs.

Statistical analysis. The Mann-Whitney U test was used to compare the pre-operative age, UCLA activity and BMI, and the post-operative outcomes for UCLA activity, OHS, EQ-VAS, and EQ-5D. Fisher's exact test was used to compare pre-operative gender, the distribution of revisions and the responses to the questionnaire on participation in running, sport, heavy manual labour and overall satisfaction with the surgery. The Wilcoxon ranked-pairs test was used for paired comparisons of OHS and UCLA activity scores with the previous study ${ }^{16}$ within each group. The association of BMI and outcome (UCLA activity, OHS, EQ-VAS) was assessed using the Spearman rank correlation. Statistical analyses were performed in conjunction with a statistician. A p-value of $<0.05$ was considered statistically significant.

\section{Results}

Of the hybrid THRs, nine had been revised, four patients had died and five were lost to follow-up, leaving 36 of $54(67 \%)$ available for review. Of the BHRs, one patient had died, five had been revised and five were lost to follow-up, leaving 43 of $54(80 \%)$ available for review. The mean follow-up for the hybrid THRs was 10.7 years (7.5 to 14.5$)$ and for the BHRs it was nine years (8.2 to 10.3 ). The medical records of the patients who had died or were lost to follow-up indicated satisfactory clinical performance at their last review. 
Table I. Classification of radiological appearance of femoral component after metal-on-metal resurfacing ${ }^{16}$

\begin{tabular}{|c|c|}
\hline $\begin{array}{l}\text { Classification } \\
\text { type }\end{array}$ & Radiological appearance \\
\hline 0 & No change \\
\hline 1 & Pedestal sign but no migration \\
\hline a & Sclerotic line confined to curved tip of stem \\
\hline$b$ & $\begin{array}{l}\text { Sclerotic line confined to distal } 1 \mathrm{~cm} \text { of shaft of } \\
\text { stem }\end{array}$ \\
\hline c & $\begin{array}{l}\text { Sclerotic line } \pm \text { symmetrical lucent lines, extending } \\
\text { proximally beyond distal } 1 \mathrm{~cm} \text { of shaft }\end{array}$ \\
\hline 2 & $\begin{array}{l}\text { Migration, usually into varus with asymmetrical } \\
\text { lucent lines }\end{array}$ \\
\hline 3 & Displaced fracture \\
\hline
\end{tabular}

In order to check that no bias had been introduced through loss to follow-up, the matching of the remaining patients in the cohorts was analysed. This revealed no differences in pre-operative age, gender and activity level but the BMI was significantly lower in the patients with a BHR (median $26.1 \mathrm{~kg} / \mathrm{m}^{2}$ in BHRs versus $28.7 \mathrm{~kg} / \mathrm{m}^{2}$ in hybrid THRs, $\mathrm{p}=0.006$ ).

Functional outcome scores. The mean OHS for the hybrid THRs was 19.1 (12 to 43) and for the BHRs 16.6 (12 to 46) $(\mathrm{p}=0.013)$ at a mean follow-up of 10.7 and nine years respectively. There was no significant change in the OHS with time.

The BHRs had significantly higher UCLA activity scores than the hybrid THRs. The mean UCLA activity score in the BHR group was 8.6 (2 to 10) and for the hybrid THRs 6.65 (3 to 10) at final follow-up $(\mathrm{p}<0.0001)$. There was no significant change in the UCLA activity score with time.

Because of the potential confounding effect of the higher BMI of the hybrid THRs on post-operative outcomes, the associations of BMI with the OHS and the UCLA activity score were analysed. With both groups combined, the BMI was weakly associated with a worse UCLA activity score $(r=-0.219)$ and OHS $(r=0.203)$, but neither association was statistically significant $(\mathrm{p}=0.056$ and $\mathrm{p}=0.075$ respectively).

The EuroQol EQ-VAS quality of life scores were significantly higher in the BHRs. The mean EQ-VAS was $82 \%$ $(30 \%$ to $100 \%)$ in the BHRs and $65.6 \%(9 \%$ to $97 \%)$ in the hybrid THRs $(\mathrm{p}=0.009)$ at final follow-up. There was no difference with the five item EuroQol questionnaire. The mean EQ-5D score was $0.78(0.06$ to 1.00$)$ in the hybrid THRs and $0.84(-0.18$ to 1.00$)$ in the BHRs.

During the four weeks before review, more patients with a BHR ran $(\mathrm{p}=0.003)$, participated in sport $(\mathrm{p}=0.004)$ and carried out heavy manual work $(\mathrm{p}=0.042)$ than patients with a hybrid THR (Table II). The overall satisfaction was similar for both groups (Table III). A total of 58\% (21 of 36) of patients with a hybrid THR and $67 \%$ (29 of 43 ) of patients with a BHR were delighted with their hip replacements $(\mathrm{p}=0.484)$.
Radiological outcomes. Of the hybrid THRs, five did not attend the outpatient clinic for radiological analysis but completed postal questionnaires. Their OHSs were 12, 12, 14, 18 and 30 . Of these patients three had undergone radiological examination at 14, 15 and 24 months before completing the questionnaires which were used for serial comparison. Therefore 34 cases had radiographs for analysis. All hybrid THRs demonstrated polyethylene wear with a mean of $1.2 \mathrm{~mm}$ (0.06 to 3.03). There was evidence of peri-articular osteolysis in 11 hips in association with polyethylene wear, with five having femoral lysis in Gruen zones 1 or 7 . Lucent lines around the femoral component were noted in these cases, but they all corresponded to the areas of lysis in zones 1 or 7 . There were no cases with lucent lines distal to these proximal zones. In two of the cases with femoral lysis there was also involvement of the acetabulum, with a further six patients having isolated acetabular lysis. Lucent lines were seen around the acetabular component in 11 hybrid THRs (32\%). No component had migrated. Stem subsidence had remained stable over the previous four years.

Of the BHRs, three patients were unable to attend for radiographs but completed a postal questionnaire. Their current OHSs were 12, 12 and 13. This left 40 radiographs of unrevised hips for analysis. Table IV summarises the radiological appearances and interval revisions from the five- ${ }^{16}$ and nine-year time-points. There was a general trend of progression of radiological appearances across the cohort. Of the nine hips with type 1c appearances at five years, ${ }^{16}$ one has been revised, three have progressed to type 2 , of whom two cases have mild symptoms, and five have not progressed radiologically and remain asymptomatic. Of the cases with type 2 change at five years, ${ }^{16}$ three of the four with varus migration have been revised because they became symptomatic or had fractured. The fourth patient has developed some pain with an OHS of 19 but has declined revision. The one with valgus migration is asymptomatic and unchanged radiologically. There was no evidence of osteolysis in any patient.

Revisions. Of the 54 hybrid THRs, nine (16.7\%) have been revised, eight for osteolysis and one for recurrent dislocation. The lysis involved the femur only in zone 7 in one case, the acetabulum only in four cases, in zone 2 in all four but additional involvement in zone 1 in one, and in zone 3 in another. Both the femur and acetabulum were involved in three cases, all in zone 7 in the femur and zone 2 in the acetabulum. An identical revision procedure was performed in these patients. In order to avoid further polyethylene wear, the bearing surfaces were changed to ceramic-on-ceramic. As ceramic liners were not available for the original acetabular shells, the shell was exchanged for a Trident component (Stryker Orthopedics). Similarly, as neither a ceramic head nor appropriate collar was available for the CPT stem, this was revised to an Exeter (Stryker Orthopedics) cement-in-cement revision component as the cement mantle was uniformly good in all cases. Areas of lysis in the proximal femur at zones 1 and 7 and in the acetabulum were bone-grafted. 
Table II. Participation in activities in the previous four weeks (number of hips, \%)

\begin{tabular}{llllllll}
\hline \multirow{2}{*}{ Activity } & & \multicolumn{2}{l}{ Trouble } & & & & \\
\cline { 2 - 6 } & Group & None & Very little & Moderate & Extreme & Impossible & Not attempted \\
\hline Running & Hybrid & $2(6)$ & $2(6)$ & $1(3)$ & $4(11)$ & $4(11)$ & $23(64)$ \\
& BHR & $13(30)$ & $8(19)$ & $2(5)$ & $3(7)$ & $2(5)$ & $15(35)$ \\
Sports & Hybrid & $11(31)$ & $3(8)$ & 0 & $3(8)$ & $2(6)$ & $17(47)$ \\
& BHR & $17(40)$ & $11(26)$ & $5(12)$ & 0 & $2(5)$ & $8(19)$ \\
Heavy manual labour & Hybrid & $6(17)$ & $5(14)$ & $6(17)$ & $3(8)$ & 0 & $16(44)$ \\
& BHR & $17(40)$ & $11(26)$ & $2(5)$ & $1(2)$ & $1(2)$ & $11(26)$ \\
\hline
\end{tabular}

* BHR, Birmingham hip resurfacing

Table III. Patient satisfaction with the prostheses (number of hips, \%)

\begin{tabular}{llllll}
\hline & & & & \multicolumn{2}{c}{ Disappointed } \\
\cline { 4 - 6 } Group & Delighted & Pleased & Satisfied & A little & Very \\
\hline Hybrid & $21(58)$ & $4(11)$ & $7(19)$ & $4(11)$ & 0 \\
BHR $^{*}$ & $29(67)$ & $8(19)$ & 0 & $5(12)$ & $1(2)$ \\
\hline
\end{tabular}

* BHR, Birmingham hip resurfacing

The previous study ${ }^{16}$ identified nine cases with osteolysis at five years. Of these, three revisions were planned and have been performed; one further case had been revised before the current review and two are now awaiting revision following the most recent assessment. The final three patients remain under review because they have not progressed in terms of wear or lysis and are asymptomatic.

Of the 54 BHRs five $(9.3 \%)$ have been revised, all for collapse of the femoral head secondary to avascular necrosis. All five had either type $1 \mathrm{c}$ or type 2 radiological changes at five years. ${ }^{16}$ Of these cases two presented acutely with displaced fractures whilst in the remaining three the decision was made electively to revise after they presented with pain. When all the failures of the first 63 cases are included, eight of $63(12.7 \%)$ have been revised of which six $(9.5 \%)$ were for avascular necrosis, of whom three $(4.8 \%)$ had consequently fractured and presented acutely, and two $(3.2 \%)$ for a fracture at six weeks.

Potential revisions. We intend to revise eight hybrid THRs for pain, wear and osteolysis. These are the eight cases with acetabular lysis described in the radiological outcomes section earlier.

Table $\mathrm{V}$ records the breakdown of revisions and impending revisions according to the acetabular component and type of head. The Harris-Galante and Zweymuller components accounted for the majority of failures. The use of a ceramic head did not appear to protect against revision, although the numbers are too small to draw reliable conclusions.

New symptoms of varying severity which could indicate a failing arthroplasty have been reported in eight BHRs, six male and two female, with OHS scores of $14,15,17,19$, 19, 24, 26 and 44. Their radiological appearances were 1c,
Table IV. Radiological appearances and revisions for patients with Birmingham hip resurfacing. The percentages of the total number, excluding those lost to follow-up and those who refused radiographs, are given in parentheses. The three hips that were revised prior to the start of the study are not included

\begin{tabular}{lrrr}
\hline & \multicolumn{3}{c}{$\begin{array}{l}\text { Interval revisions with } \\
\text { appearance immediately }\end{array}$} \\
Status & Five years $\begin{array}{l}\text { prior to revision } \\
\text { Nine years }\end{array}$ \\
\hline $\begin{array}{l}\text { Loss to follow-up or } \\
\text { death }\end{array}$ & 1 & 6 \\
Declined radiographs & 1 & 3 \\
& & & \\
Radiological & & & \\
appearance & $16(30.8)$ & $4(8.9)$ \\
$\quad$ Type 0 & $6(11.5)$ & $4(8.8)$ & $8(17.8)$ \\
$\quad$ Type 1a & $9(17.3)$ & 1 & $19(42.2)$ \\
$\quad$ Type 1b & $5(9.6)$ & 2 & $5(11.1)$ \\
$\quad$ Type 1c & 0 & 2 & $5(11.1)$ \\
$\quad$ Type 2 & & \\
$\quad$ Type 3/Revised & 0 &
\end{tabular}

$1 \mathrm{a}, 1 \mathrm{~b}, 2,2,1 \mathrm{~b}, 1 \mathrm{~b}$ and $1 \mathrm{~b}$ respectively. There had been no change in six over the previous four years including one type 2 pedestal, and two had progressed; $1 \mathrm{c}$ to 2 and $1 \mathrm{~b}$ to $1 \mathrm{c}$, respectively. Of the two cases with type 2 pedestals, one had an increase in the OHS of one point only, and the other of five points between five and nine years. There was no evidence of infection in any of the eight cases. They were all investigated by ultrasound or MRI and none had radiological evidence of pseudotumour. They remain under review. The serum metal ions were not measured.

Of these eight cases, one female (OHS 44, pedestal $1 \mathrm{~b}$ ) had always had a painful BHR. Her symptoms had not deteriorated but further investigation for pseudotumour was performed and was negative. A male patient was explored for groin pain and a recent onset of sciatic nerve palsy but there was no evidence of component loosening or pseudotumour. The sciatic nerve was adherent to dense scar tissue. It was released and a neurolysis performed which improved the palsy and pain. Histological examination of tissue adjacent to the hip joint revealed no evidence of aseptic lymphocytic vasculitis-associated lesion (ALVAL) or infection. His femoral component demonstrated a 1c pedestal sign on plain radiographs. 
Table V. Revision and impending revision rates at a mean follow-up of 10.7 years in the hybrid total hip

replacement group

\begin{tabular}{lllllc}
\hline Acetabular component & Head type & Number & Revised & $\begin{array}{l}\text { Impending } \\
\text { revision }\end{array}$ & $\begin{array}{l}\text { \% revised and } \\
\text { impending }\end{array}$ \\
\hline Harris-Galante $^{*}$ & Metal & 26 & 5 & 6 & 42 \\
Harris-Galante $^{*}$ & Ceramic & 3 & 1 & 0 & 33 \\
Zweymuller $^{\dagger}$ & Metal & 7 & 1 & 2 & 43 \\
ABG $^{\ddagger}$ & Metal & 10 & 0 & 0 & 0 \\
ABG $^{\ddagger}$ & Ceramic & 6 & 1 & 0 & 17 \\
PFC $^{\S}$ & Metal & 1 & 1 & 0 & 100 \\
Hedrocel & Metal & 1 & 0 & 0 & 0 \\
\hline * Zimmer, Warsaw, Indiana & & & & \\
† PLUS Orthopedics, Rotkreuz, Switzerland & & & \\
‡ Stryker Orthopedics, Mahwah, New Jersey & &
\end{tabular}

Thus of the original 54 hybrid THRs, we have revised, explored or intend to revise $17(31.5 \%)$ and of the 63 BHRs, nine $(14.3 \%)$. Both groups have further cases that require close radiological follow-up. Hybrid THRs have so far created a greater revision burden than BHRs $(\mathrm{p}=0.022)$.

\section{Discussion}

The cemented hip arthroplasty may fail prematurely in patients with osteoarthritis under the age of $50^{24}$ and, although better results have been reported with impaction grafting ${ }^{25}$ and $22.25 \mathrm{~mm}$ bearings, ${ }^{26}$ loosening and wear remain the major complications. ${ }^{27}$ Loosening has been successfully addressed by porous-coated hemispherical acetabular components ${ }^{28-30}$ but at the price of increased polyethylene wear and osteolysis. ${ }^{27,29,30}$ Wear has been reduced by hard bearing surfaces which reduce osteolysis at the expense, in some cases, of pseudotumour formation. ${ }^{8}$

This study gives a medium-term comparison of hybrid THR with bone preserving metal-on-metal large head devices in a young active population. Other similar comparisons have had follow-ups of less than three years. ${ }^{9-14}$ Both strategies continue to be used. The BHR has the lowest rate of revision of the hip resurfacings ${ }^{31}$ and remains a reasonable choice of implant. There are better hybrid uncemented metal-backed acetabular components currently available than the ones used in this study. ${ }^{32-34}$

The weak link of the BHR was the femoral component and of the hybrid THR polyethylene wear. The HarrisGalante was particularly prone to wear. None of the acetabular components of the BHRs required revision. The femoral components of the hybrid THRs were revised purely to enable a ceramic-on-ceramic articulation, and not because they were loose. In our hands, the cemented CPT femoral component has been very reliable in younger patients. ${ }^{35}$ Among the BHRs, there were two early failures from fracture of the femoral neck within six weeks and one at one year due to avascular necrosis. These have been included to allow comparison of the revision burden of the two devices. The fractures occurred during the learning curve of the senior surgeon and have been noted by other authors as being more prevalent early in a surgeon's experience. ${ }^{36}$ The failures of the BHR have tended to be symptomatic and early. The principal mode has been avascular necrosis with no pseudotumours. Eight BHRs are painful and, despite investigation for infection and pseudotumour, currently show no clear indication for revision.

The hybrid THRs are showing wear and osteolysis resulting from the polyethylene used at the time. Failure has tended to occur later and be asymptomatic. The metal shell increases polyethylene wear, and while modern highly crosslinked polyethylene may be more durable, it will not save the young active patient from a revision arthroplasty unless it adds at least ten years to the survival of the bearing surface.

We anticipate increasing failure from both groups. Our experience with the hybrid THRs from a previous study suggests that the polyethylene will continue to wear with $50 \%$ of arthroplasties requiring revision by 15 years. ${ }^{29}$ Half of the pedestal signs in the BHRs are progressive. We were uncertain of the significance of the changes observed and classified in our previous study. ${ }^{16}$ The current assessment suggests that cases which develop type $1 \mathrm{c}$ and 2 changes with varus migration are likely to fail. We would advocate careful counselling of patients with type 2 changes with a low threshold for revision before fracture occurs, and close radiological surveillance of type $1 \mathrm{c}$ cases.

The weaknesses of this study are that it is not randomised and may have inherent bias because the patients with a BHR were not restricted in heavy manual work or sport, whereas such activity was discouraged in those with a hybrid THR, because of concerns regarding wear. In fact, many of the patients with a hybrid THR $(37 \%)$ disregarded the restrictions suggested. ${ }^{15}$ Our data demonstrate that the patients with a BHR achieved higher levels of activity than those with a hybrid THR, without an apparent increase in the rate of failure in the mid-term. The better UCLA activ- 
ity and OHS scores achieved by the patients with a BHR may also be biased by loss to follow-up and the consequent difference in BMI of the two groups, which had a negative association with performance; however, this association did not reach statistical significance whereas the superior performance of the BHRs was of strong significance. There is a shorter follow-up for the BHR group which reflects a change in the senior author's practice as resurfacing became the first choice for the young patient.

The BHRs continue to maintain superior function to the hybrid THRs and have a lower rate of revision. While the indications for resurfacing may have narrowed, our data suggest that the BHR remains a reasonable option for the young adult with end-stage osteoarthritis of the hip.

\section{Listen live}

Listen to the abstract of this article at

www.jbjs.org.uk/interactive/audio

The authors would like to thank Dr T. Kozak, Emeritus Professor of Statistics at the University of British Columbia for his help with statistical analysis.

No benefits in any form have been received or will be received from a commercial party related directly or indirectly to the subject of this article.

\section{References}

1. Amstutz HC, Le Duff MJ. Hip resurfacing results for osteonecrosis are as good as for other etiologies at 2 to 12 years. Clin Orthop 2010;468:375-81.

2. Daniel J, Ziaee H, Kamali A, et al. Ten-year results of a double-heat-treated metalon-metal hip resurfacing. J Bone Joint Surg [Br] 2010;92-B:20-7.

3. McMinn D, Daniel J, Ziaee H, Pradhan C. Hip resurfacing. In: Bentley G, ed. European instructional lectures: 11 EFORT Congress, Madrid, Spain. New York: SpringerVerlag, 2010:133-42.

4. Shimmin AJ, Back D. Femoral neck fractures following Birmingham hip resurfacing a national review of 50 cases. J Bone Joint Surg [Br] 2005;87-B:463-4.

5. Treacy RB, McBryde CW, Pynsent PB. Birmingham hip resurfacing arthroplasty: a minimum follow-up of five years. J Bone Joint Surg [Br] 2005;87-B:167-70.

6. Daniel J, Pynsent PB, McMinn DJ. Metal-on-metal resurfacing of the hip in patients under the age of 55 years with osteoarthritis. J Bone Joint Surg [Br]2004;86B:177-84

7. Amstutz HC, Beaulé PE, Dorey FJ, et al. Metal-on-metal hybrid surface arthroplasty: two to six-year follow-up study. J Bone Joint Surg [Am]2004;86-A:28-39.

8. Pandit H, Glyn-Jones S, McLardy-Smith $\mathbf{P}$, et al. Pseudotumours associated with metal-on-metal hip resurfacings. J Bone Joint Surg [Br] 2008;90-B:847-51.

9. Garbuz DS, Tanzer M, Greidanus NV, Masri BA, Duncan CP. The John Charnley Award: metal-on-metal hip resurfacing versus large-diameter head metal-on-metal total hip arthroplasty: a randomized clinical trial. Clin Orthop 2010;468:318-25.

10. Lavigne $\mathbf{M}$, Therrien $\mathbf{M}$, Nantel J, et al. The John Charnley Award: the functional outcome of hip resurfacing and large-head THA is the same: a randomized, doubleblind study. Clin Orthop 2010;468:326-36.

11. Lavigne M, Masse V, Girard J, Roy AG, Vendittoli PA. Return to sport after hip resurfacing or total hip arthroplasty: a randomized study. Rev Chir Orthop Reparatrice Appar Mot 2008;94:361-7 (in French).

12. Vendittoli PA, Lavigne M, Roy AG, Lusignan D. A prospective randomized clinical trial comparing metal-on-metal total hip arthroplasty and metal-on-metal total hip resurfacing in patients less than 65 years old. Hip Int 2006;16(Suppl 4):73-81.
13. Vail TP, Mina CA, Yergler JD, Pietrobon R. Metal-on-metal hip resurfacing compares favorably with THA at 2 years followup. Clin Orthop 2006;453:123-31.

14. Mont MA, Marker DR, Smith JM, Ulrich SD, McGrath MS. Resurfacing is comparable to total hip arthroplasty at short-term follow-up. Clin Orthop 2009;467:66-71.

15. Pollard TCB, Basu C, Ainsworth R, Lai W, Bannister GC. Is the Birmingham Hip Resurfacing worthwhile? Hip Int 2003;13:25-8.

16. Pollard TCB, Baker RP, Eastaugh-Waring SJ, Bannister GC. Treatment of the young active patient with osteoarthritis of the hip: a five- to seven-year comparison of hybrid total hip arthroplasty and metal-on-metal resurfacing. J Bone Joint Surg [Br] 2006;88-B:592-600.

17. Amstutz HC, Thomas BJ, Jinnah R, et al. Treatment of primary osteoarthritis of the hip: a comparison of total joint and surface replacement arthroplasty. J Bone Joint Surg [Am] 1984;66-A:228-41.

18. Dawson J, Fitzpatrick R, Murray D, Carr A. Comparison of measures to assess outcomes in total hip replacement surgery. Qual Health Care 1996;5:91-8.

19. Brooks R. EuroQol: the current state of play. Health Policy 1996;37:53-72.

20. DeLee JG, Charnley J. Radiological demarcation of cemented sockets in total hip replacement. Clin Orthop 1976;121:20-32.

21. Gruen TA, McNeice GM, Amstutz HC. "Modes of failure" of cemented stem-type femoral components: a radiographic analysis of loosening. Clin Orthop 1979;141:17-

22. Johnston RC, Fitzgerald RH Jr, Harris WH, et al. Clinical and radiographic evaluation of total hip replacement: a standard system of terminology for reporting results. $J$ Bone Joint Surg [Am] 1990;72-A:161-8.

23. Dorr LD, Wan Z. Comparative results of a distal modular sleeve, circumferential coating, and stiffness relief using the Anatomic Porous Replacement II. J Arthroplasty 1996;11:419-28

24. Herberts P, Kärrholm J, Garellick G. The Swedish National Arthroplasty Register, Annual Report 2004. http://www.jru.orthop.gu.se (date last accessed 20 October 2010).

25. de Kam DC, Gardeniers JW, Veth RP, Schreurs BW. Good results with cemented total hip arthroplasty in patients between 40 and 50 years of age. Acta Orthop 2010;81:165-70.

26. Sochart DH, Porter ML. The long-term results of Charnley low-friction arthroplasty in young patients who have congenital dislocation, degenerative osteoarthrosis, or rheumatoid arthritis. J Bone Joint Surg [Am] 1997;79-A:1599-617.

27. Hartofilakidis G, Georgiades G, Babis GC. A comparison of the outcome of cemented all-polyethylene and cementless metal-backed acetabular sockets in primary total hip arthroplasty. J Arthroplasty 2009;24:217-25

28. Parvizi J, Sullivan T, Duffy G, Cabanela ME. Fifteen-year clinical survivorship of Harris-Galante total hip arthroplasty. J Arthroplasty 2004;19:672-7.

29. Utting MR, Raghuvanshi M, Amirfeyz R, et al. The Harris-Galante porous-coated, hemispherical, polyethylene-lined acetabular component in patients under 50 years of age: a 12- to 16-year review. J Bone Joint Surg [Br] 2008;90-B:1422-7.

30. Della Valle CJ, Mesko NW, Quigley L, et al. Primary total hip arthroplasty with a porous-coated acetabular component: a concise follow-up, at a minimum of twenty years, of previous reports. J Bone Joint Surg [Am] 2009;91-A:1130-5.

31. No authors listed. 6th Annual Report: National Joint Registry of England and Wales, 2009. http://www.njrcentre.org.uk (date last accessed 20 October 2010).

32. Lazarinis S, Kärrholm J, Hailer NP. Increased risk of revision of acetabular cups coated with hydroxyapatite. Acta Orthop 2010;81:53-9

33. Curry HG, Lynskey TG, Frampton CM. Harris-Galante II acetabular cup: a survival analysis. J Orthop Surg [Hong Kong) 2008;16:201-5.

34. Eskelinen A, Remes V, Helenius I, et al. Uncemented total hip arthroplasty for primary osteoarthritis in young patients: a mid-to long-term follow-up study from the Finnish Arthroplasty Register. Acta Orthop 2006;77:57-70.

35. Burston BJ, Yates PJ, Hook S, et al. Cemented polished tapered stems in patients less than 50 years of age: a minimum 10-year follow-up. J Arthroplasty 2010;25:692-

36. Della Valle CJ, Nunley RM, Raterman SJ, Barrack RL. Initial American experience with hip resurfacing following FDA approval. Clin Orthop 2009;467:72-8. 